\title{
New Predictors of the Metabolic Syndrome in Children-Role of Adipocytokines
}

\author{
ANTJE KÖRNER, JÜRGEN KRATZSCH, RUTH GAUSCHE, MICHAEL SCHAAB, SANDRA ERBS, AND WIELAND KIESS
}

University Hospital for Children and Adolescents [A.K., W.K.], Institute of Laboratory Medicine [J.K., M.S.], Clinical Chemistry and Molecular Diagnosis, CrescNet gGmbH [R.G.], Department of Cardiology-Heart Center Leipzig [S.E.], University of Leipzig, 04317

Leipzig, Germany

\begin{abstract}
There is ample discussion of the relevance of the metabolic syndrome, the definition criteria, and predictive power. Nevertheless, along with the increasing prevalence of childhood obesity, the prevalence of the metabolic syndrome in obese children is reported at $30 \%$, irrespective of the definition applied. Because children are otherwise relatively free of co-morbidities, they constitute an interesting population in which to study the sequence of events of obesity-related pathology. The adipocytokines appear to be important in this respect. Leptin was initially suggested as a promising "antiobesity" hormone. New concepts indicate that, in humans, leptin and its soluble receptor may be more important in states of energy deficiency rather than a predictor of the metabolic syndrome. Adiponectin, on the other hand, is not only related to obesity and insulin resistance, but appears to be the strongest predictor for metabolic syndrome, even in children. In newborns and infants, both adipocytokines occur in high concentrations, even though this cannot completely explain the increased risk for ensuing metabolic disease later in life. Finally, low-grade systemic inflammation may underlie the clustering of metabolic risk factors, but their role in children remains to be specified. Overall factors from the adipose tissue may constitute not only markers but also mediators of metabolic sequelae of obesity. (Pediatr Res 61: 640-645, 2007)
\end{abstract}

$\mathrm{T}$ he metabolic syndrome in children is not only a scientifically and clinically relevant issue but also a controversial and complex issue with many questions not satisfactorily answered, such as, "What is the metabolic syndrome?" "How is the situation in children?" "How can we predict it?" and "Does the adipose tissue contribute to it?"

\section{TERMS AND DEFINITION OF THE METABOLIC SYNDROME}

The term and concept of the metabolic syndrome was first introduced by Reaven in 1988 (1), when he noticed, from the

Received August 1, 2006; accepted October 19, 2006.

Correspondence: Antje Körner, M.D., University Hospital for Children and Adolescents, University of Leipzig, Oststrasse 21-25, 04317 Leipzig, Germany; e-mail: antje.koerner@medizin.uni-leipzig.de

This work was supported by grants from the Deutsche Forschungsgemeinschaft (DFG) KFO-152: "Atherobesity," KO 3512/1-1 (TP1), from the Interdisciplinary Center for Clinical Research at the University of Leipzig (B21 to A.K.), and from the European Community "PIONEER" (to W.K.). The Leipzig schoolchildren project was supported by unrestricted grants from Pfizer Pharma GmbH and Novo Nordisk GmbH to W.K. Part of the study was supported by a research grant from the German Hypertension Association to A.K.

DOI: $10.1203 / 01 . p d r .0000262638 .48304 . e f$ analysis of experimental, clinical, and epidemiologic studies, the simultaneous occurrence of hyperinsulinemia with several other cardiovascular risk factors in the same patient and that this clustering results in a markedly higher cardiovascular morbidity. He already assumed that there might be one common underlying mechanism for those risk factors-insulin resistance. Certainly, obesity seems to be another strong predisposing factor for all those components. The concept of the metabolic syndrome was then defined and institutionalized and was widely applied in clinical medicine (2-4). However, recent re-evaluation lead to a critical appraisal of the term and questioned the concept of the metabolic syndrome. In a joint statement of the American Diabetes Association and the European Association of the Study of Diabetes, the clarity and accuracy of the existing definition was questioned (5). Some criteria used are ambiguous or incomplete, and it has not been proven that the predictive value of the "syndrome" over the predictive value of the single components themselves is actually higher. In addition, ongoing research has identified more components that would be worthwhile to consider, including cytokines and adipocytokines.

Nevertheless, there is no doubt that there is a clustering of risk factors that correlate with each other and are associated with cardiovascular disease, and certainly obesity and insulin resistance constitute major risk factors.

\section{THE METABOLIC SYNDROME IN CHILDREN}

The metabolic syndrome has been regarded as a syndrome of multi-morbid adults. In pediatric medicine, we increasingly see obese children and adolescents with impaired glucose tolerance, hypertensive blood pressure levels, dyslipidemia, and hyperuricemia. Hence, no matter what definition is applied, there is a portion of obese children at high risk for cardiovascular disease. These may be regarded as extreme cases, but they are no longer sporadic examples. The increase in the prevalence of obesity in children is well known $(6,7)$. This phenomenon is demonstrated by the dynamic long-term alterations in BMI centiles. Comparing BMI centiles $15 \mathrm{y}$ apart, there was a clear rise in the 97th centile over time, whereas the 3rd and 50th centiles remained stable over the

Abbreviations: SGA, small for gestational age; AGA, adequate for gestational age; SDS, standard deviation score; NASH, nonalcoholic steatohepatitis; sOB-R, soluble leptin receptor; $\mathbf{C r P}$, C-reactive protein 


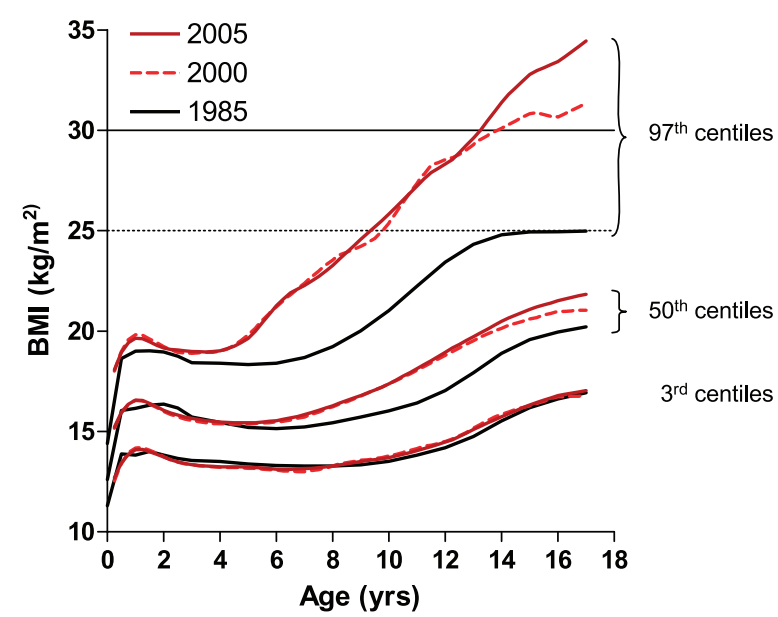

Figure 1. Secular trends in BMI centiles over two centuries in central Germany. BMI centiles of girls in the year 1985 (Hesse) are compared with the years $2000(n=30,029)$ and $2005(n=68,527)$ (CrescNet). The divergence of the 97th centile begins at preschool age, about 3-6 y, whereas the 3rd and 50th centiles remain stable over the years.

same period of time (Fig. 1). This indicates not only that more children become obese, but, in addition, that the degree of obesity increases $(8,9)$. The 97 th centile crosses the adult cut-off of $25 \mathrm{~kg} / \mathrm{m}^{2}$ at an age range of about $10 \mathrm{y}$, and by $14 \mathrm{y}$ 97 th centile exceeds $30 \mathrm{~kg} / \mathrm{m}^{2}$.

With the increasing prevalence of obesity, we will have to and already do face the consequences of obesity at a much younger age. In our cohort of obese children, we saw a high prevalence of metabolic pathology. One third had signs of insulin resistance that correlated with BMI, and many had dyslipidemia (Table 1). This is in agreement with many other studies, such as by Sinha (10), and is also seen in other German Caucasian cohorts $(11,12)$.

Another important component is blood pressure and hypertension, which is not currently well investigated in children. In a large cross-sectional study of about 2500 children, we identified a mild but continuous increase in the prevalence of hypertensive blood pressure levels that sharply raised when children became overweight (13). It also appears that cardio-

Table 1. Incidence of metabolic disorders in obese Caucasian children of central Germany

\begin{tabular}{lccc}
\hline \multicolumn{1}{c}{ Parameter } & $\begin{array}{c}\text { Patients with } \\
\text { pathology }(\%)\end{array}$ & BMI, $r$ & $\begin{array}{c}\text { BMI } \\
\text { SDS, } r\end{array}$ \\
\hline Impaired glucose tolerance & 18.3 & $0.12^{*}$ & NS \\
Hyperinsulinemia & & & \\
$\quad$ Peak insulin $>1000 \mathrm{pmol} / \mathrm{L}$ & 40.4 & $0.24 \dagger$ & $0.11^{*}$ \\
$\quad$ Fasting insulin $>158 \mathrm{pmol} / \mathrm{L}$ & 11.0 & $0.45 \dagger$ & $0.19 \dagger$ \\
Insulin resistance HOMA-IR $>3.0$ & 33.6 & $0.46 \dagger$ & $0.18 \dagger$ \\
Hyperuricemia & 25.4 & $0.52 \dagger$ & $0.18 \dagger$ \\
Hypertriglyceridemia & 22.5 & $\mathrm{NS}$ & $\mathrm{NS}$ \\
Hypercholesterinemia & 12.1 & $\mathrm{NS}$ & $0.13 \ddagger$ \\
Elevated liver enzymes & 16.1 & $0.18 \dagger$ & $\mathrm{NS}$ \\
\hline
\end{tabular}

Data are shown for $n=307$ consecutive obese children (BMI SDS $\geq 1.88$ SDS) of the University Hospital for Children and Adolescents Leipzig, Germany. Pearson's correlation coefficient for $n=398$ oGTTs was calculated, referring to BMI and BMI SDS indicating the degree of obesity.* $p<$ $0.05 ; \dagger p<0.0001 ; \ddagger p<0.01$.

HOMA-IR, homeostasis model assessment-insulin resistance; OGGTs, oral glucose tolerance test. vascular risk factors cluster in children, as shown in other studies, which similarly observed that about one third of overweight and obese children had classical cardiovascular risk factors such as dyslipidemia and particularly BMI dependent hypertension (14). There are few studies that aimed to define the metabolic syndrome in children, which is probably even more difficult than in adults since the selection and the cut-offs of the parameters are even more arbitrary. These studies uniformly show that the metabolic syndrome is a disorder highly prevalent in the pediatric population (Table 2) (15-18). Hence, almost all sequelae of obesity-related disorders develop already in childhood (Fig. 2).

\section{NONALCOHOLIC STEATOHEPATITIS (NASH)-A NEW COMPONENT OF THE METABOLIC SYNDROME?}

In addition to these classical components of the metabolic syndrome, there is increasing concern about the emergence of NASH in obese children. Nonalcoholic fatty liver disease was found in $55 \%$ (19) to $77 \%$ of obese children with about $24 \%$ already suffering from NASH (20). Recent studies suggest that insulin resistance and oxidative stress are important in the pathogenesis of NASH and that NASH may hence be considered as the hepatic manifestation of the metabolic syndrome (21). As in adults, NASH in children may progress to cirrhosis associated in later life in about $20 \%$ and $30-40 \%$ of patients with NASH cirrhosis will experience liver-related death (22). Hence, this condition deserves consideration in the work-up for co-morbidities in obese children. Currently, there is, however, no recommendation on pharmacological intervention in children. Because both long-term studies on the clinical course and treatment options are lacking, life-style (dietary) intervention is of high importance (23).

\section{PREDICTORS FOR THE METABOLIC SYNDROME IN CHILDREN-FACTORS FROM ADIPOSE TISSUE}

Considering this early increase in obesity prevalence and that the fact that children are otherwise relatively free of co-morbidities and usually treatment naïve, they constitute an interesting and valuable population to study the sequence of events leading to obesity-related pathology. Particularly, research into the mechanisms and mediators of obesity-related sequelae has greatly expanded over the last years and, in this respect, factors released from adipose tissue appear to be particularly important. These compounds, such as inflammatory components and cytokines, fatty acids and, of course, the adipocytokines, exert biologic actions beyond the adipose tissue and many directly influence peripheral metabolic, vascular and endocrine processes $(24,25)$.

Leptin. Leptin was the first of the classical adipocytokines detected (26). It was initially very promising, with actions to reduce food intake and to increase energy expenditure and thereby reduce body weight in rodents, as has extensively been reviewed elsewhere (27). In humans, the effects of leptin in obese people were disappointing (28). However, there are new interesting aspects emerging, particularly the effect of leptin on vasculature and endothelial cells by interaction with 
Table 2. Overview of the incidence of metabolic syndrome in children in representative studies

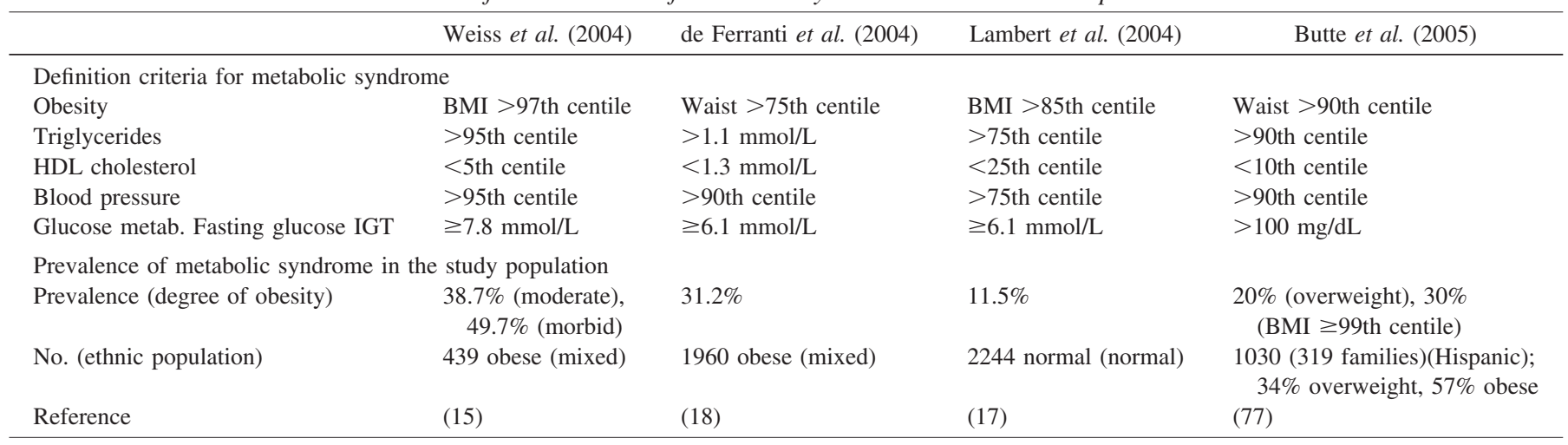

Definition criteria for metabolic syndrome are shown in the upper part of the table. Metabolic syndrome was defined as having three or more of the components. Cut-off levels for the respective studies are given. IGT, impaired glucose tolerance.

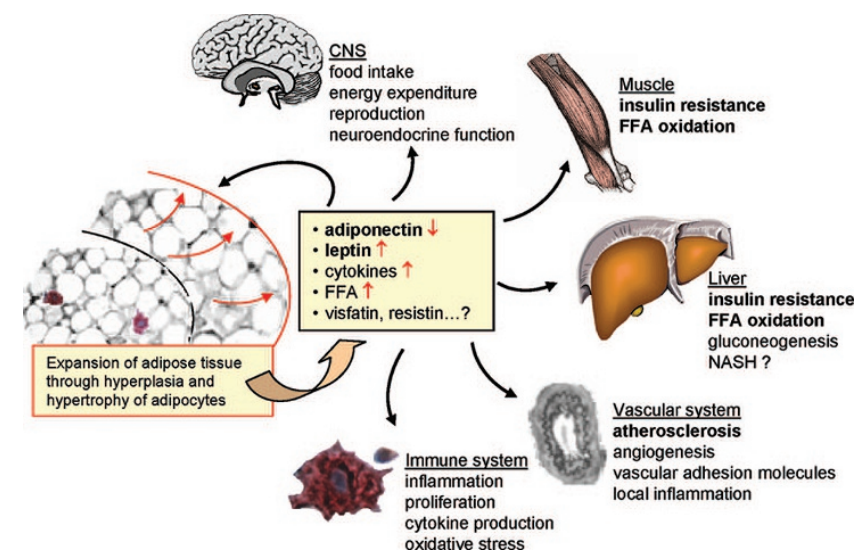

Figure 2. Contribution of adipocytokines to components of the metabolic syndrome. The schematic overview illustrates interactions of adipocytokines (which are not listed completely) with peripheral and central metabolic processes. Some effects of leptin and adiponectin are specified in Table 3 and are reviewed elsewhere.

Table 3. Effects of leptin and adiponectin on metabolic, cardiovascular, and immune function

\begin{tabular}{llc}
\hline \multicolumn{1}{c}{ Leptin } & Adiponectin \\
\hline$(\downarrow)$ & Insulin sensitivity & $\uparrow$ \\
$\downarrow$ & Food intake & $\rightarrow$ \\
$\downarrow$ & Body weight & $\rightarrow$ \\
$\uparrow$ & Dyslipidemia & $\downarrow$ \\
$\uparrow$ & Energy expenditure & $\downarrow$ \\
$\uparrow$ & Cell proliferation & $\downarrow$ \\
$\uparrow$ & (Vascular) inflammation & $\downarrow$ \\
Angiogenesis $\uparrow$ & & \\
Thermogenesis $\uparrow$ & & \\
SNS activity $\uparrow$ & & \\
Reproduction $\downarrow$ & & \\
\hline
\end{tabular}

pathways of oxidative stress, nuclear factor- $\kappa \mathrm{B}$, endothelin, and others, which is also relevant in humans as reviewed elsewhere (29). It is well known that leptin levels correlate closely with BMI in both adults and children. In addition, there are associations of leptin with metabolic parameters such as insulin resistance indices (HOMA-IR) or lipids. This may, however, be mainly attributable to the underlying association with fat mass.
Another player in the leptin system is the sOB-R, which may play an important role in the regulation and modulation of leptin action. We identified specific binding of leptin to its soluble receptor in human plasma and confirmed that this is the major leptin binding protein in human serum (30). To evaluate the biologic and cellular relevance of leptin binding to its soluble receptor, we applied a system of hematopoietic cells transfected with full-length human leptin receptor, in which leptin exerted a pronounced and dose-dependent proliferative response (31). If sOB-R was added to the system, the proliferation exerted by leptin was blocked when sOB-R was present in excess (31). To evaluate the physiologic and pathophysiological relevance of these complexes in children, we first analyzed normal children and saw that the sOB-R decreased with age, whereas leptin strongly increased during puberty (32). Expectedly, obese children had higher leptin levels compared with lean children. In contrast to this, the sOB-R serum levels were significantly lower in the obese children (33). There are, however, situations in which the molar excess of sOB-R over leptin is remarkably high. We identified high sOB-R excess in neonates in the phase of postnatal weight loss (34) in children with manifestation of type 1 diabetes, where it decreased when the metabolism was corrected by giving insulin (35). These are situations of high energy demand and/or energy deficiency. More direct evidence for this notion was provided by a recent study in malnourished children that presented with high ratios of sOB-R over leptin that declined after re-feeding (36). Hence, one may hypothesize that this regulation of leptin by the sOB-R, possibly the whole leptin system, is more important in states of energy deficiency rather than being a predictor of the metabolic syndrome (37).

Adiponectin. Much more promising with respect to counteracting the metabolic syndrome is the adipocytokine adiponectin. Adiponectin is an adipocytokine that is exclusively expressed by adipocytes and circulates in very high concentrations in human serum. In contrast to most other adipocytokines, it exerts profound beneficial actions in that it has antiatherogenic, antidiabetogenic, and anti-inflammatory/proliferative effects and thereby protects against the development of type 2 diabetes and cardiovascular disease $(38,39)$. 
It is decreased in obesity and these decreased adiponectin levels are associated with parameters of the metabolic syndrome in adults (29). Because it is also known that men have significantly lower adiponectin than women, we evaluated the course of adiponectin during pubertal development. In boys, there was a remarkable decline in adiponectin levels with the progression of puberty that eventually resulted in significantly lower adiponectin levels in boys compared with girls after completion of puberty (40). Thus, gender and pubertal stage need to be considered when comparing adiponectin levels between lean and obese children. Not surprisingly, adiponectin levels were markedly decreased in obese children. In a stepwise multiple regression analysis aimed to identify independent predictors in obese children, adiponectin levels closely correlated with parameters of insulin resistance, dyslipidemia, and the proinsulin:insulin ratio that override the effects of BMI and pubertal development seen in the lean children (40-42). Particularly, the high-molecular-weight complex reflects metabolic abnormalities associated with childhood obesity (43).

In addition to metabolic parameters, adiponectin was also negatively associated with intima media thickness in children, which is an early indicator of developing and existing vascular damage (44). Hence, in all these studies there is a clear association of low adiponectin levels with cardiovascular risk factors. In studies investigating whether adiponectin actually predicts the presence or occurrence of metabolic syndrome in children, adiponectin levels lower than the median were actual the strongest predictor of metabolic syndrome, with an odds ratio of $10(45,46)$. Thus, adiponectin is obviously a very early predictor of metabolic syndrome in children.

Considering this important role of adiponectin, the regulation of adiponectin expression becomes interesting. Adiponectin is exclusively expressed by adipocytes; still, the expression and serum levels are decreased in obesity (29). It is also known that obesity results not only from hypertrophy but also from hyperplasia of adipose through the recruitment and differentiation of preadipocytes (47). While preadipocytes do not express adiponectin, expression was induced increasingly with differentiation of the adipocytes and protein expression was confirmed to be specific for mature adipocytes (48). The exposure of adipocytes to serum during the course of differentiation and acutely to mature adipocytes led to a profound suppression of adiponectin indicating a strong humoral components exist in human serum that suppress adiponectin expression. This or these components are present in the serum of lean as well as obese patients and are of high molecular weight (48). As an important metabolic regulator, adiponectin itself is controlled in conditions of metabolic stress (49) and by a number of hormones and factors involved in regulation of metabolic and/or immune function. Insulin decreases adiponectin levels in humans and in rodents, both in vivo and in vitro (50). Thiazolidindiones, as potent $\operatorname{PPAR} \gamma$ agonists, increase the expression of adiponectin $(51,52)$. Most other factors with significant impact on adiponectin regulation do exert inhibitory effects (50), as there are catecholamines, glucocorticoids (53), cytokines [IL-6 and tumor necrosis factor
(TNF)- $\alpha$ ] (53), prolactin (54), growth hormone (54), and androgens $(40,55)$.

Inflammatory cytokines. Finally, in recent years, research has elucidated that low-grade systemic inflammation may underlie, at least in part, the clustering of cardiovascular risk factors $(56,57)$. Through the production and secretion of cytokines, the adipose tissue may hence contribute to that lowgrade inflammatory state $(56,57)$.

It is well acknowledged in adults that the high-sensitive $\mathrm{CrP}$ is a good marker for low-grade inflammation that is elevated in obesity in relation to cardiovascular risk profiles (58). In obese children, many studies do also show an elevation of CrP. However, in contrast to adults, most studies in children do not conclusively confirm that $\mathrm{CrP}$ is associated with insulin resistance or metabolic risk if corrected for BMI, possibly except for lipid status (59-62). The situation is similar with other adipocytokines. TNF- $\alpha$, IL-6, and resistin are produced by adipose tissue (or adipose resident macrophages), and some, such as IL-6, in amounts relevant for serum levels (63). Accordingly, there is also an elevation of the proinflammatory cytokine IL-6 in obese children (64). For TNF- $\alpha$, the situation is less clear cut, with studies showing a positive association with body fat and others showing a decrease in obese prepubertal children $(65,66)$. Serum levels of resistin do not appear to be much changed in obesity in children (67). Overall, the BMI independent predictive value for metabolic risk factors really remains to be shown for children.

\section{ADIPOCYTOKINES IN RELATION TO BIRTH WEIGHT}

Reduced fetal growth is independently associated with an increased risk of the development of cardiovascular diseases, the insulin-resistance syndrome, or one of its components (68). Comparing the prevalence of the metabolic syndrome between young adults formerly having been SGA or AGA revealed a significant difference for all components, with metabolic syndrome observed in $2.3 \%$ of the SGA group and in 4 per 1000 of the AGA group (69). The pathophysiologic mechanisms of this association are incompletely understood, though current hypotheses point to derangements in the fetal development process of adiposity that is responsible for postnatal growth and the later development of insulin resistance.

The adipocytokine adiponectin as well as leptin are clearly detectable in breast milk and are also produced by placental and/or fetal tissue (70). Thus, the fetus and the infant are exposed to these factors, which is reflected by high serum concentrations of adiponectin and leptin in cord blood and peripheral serum $(34,71,72)$. In the first months and years of life, these initially high adiponectin and leptin serum concentrations decline $(34,73)$. There are no significant gender differences in the adipocytokine levels in newborns. As expected, cord blood and peripheral serum leptin levels are related to birth weight in several studies (74). However, as outlined above, these increased leptin levels are exceeded several-fold by sOB-R, which may preserve the fetus and/or 
infant from deleterious energy waste in a state of energy deficit (34).

In contrast to adults, in children adiponectin correlated positively with birth weight $(71,75)$. Considering that adiponectin expression increases with the differentiation of adipocytes (48), this relationship may reflect the amount of developing adipose tissue. This may also explain why adiponectin levels are lower in SGA compared with AGA newborns $(72,76)$. The contribution of circulating adiponectin to the increased risk for developing insulin resistance and diabetes in formerly SGA children is, however, not clear, and is obviously difficult to evaluate due to the array of confounding factors over time.

In summary, there is a worrying increase of obesity-related co-morbidities in children beginning from a relatively young age, even leading to the full complex of "metabolic syndrome," which is, however, difficult to define. Factors from the adipose tissue may constitute not only markers but also mediators of metabolic sequelae of obesity.

Adiponectin, so far, appears to be the strongest predictor from the adipose tissue for developing or existing metabolic syndrome, even in children, whereas the role for leptin, the initial classical adipocytokine, may be more important in states of energy deficiency than in energy excess and metabolic syndrome. Other cytokines are markers of low-grade systemic inflammation, but their role in children remains to be further specified. Children constitute a valuable study population in which to evaluate the sequence of events in obesityrelated pathophysiology and, therefore, to identify causal relationships.

Acknowledgements. The authors thank the children who participated in the studies. We also thank the technicians and study nurses for their help.

\section{REFERENCES}

1. Reaven GM 1988 Banting Lecture 1988. Role of insulin resistance in human disease. Diabetes 37:1595-1607

2. Grundy SM, Cleeman JI, Daniels SR, Donato KA, Eckel RH, Franklin BA, Gordon DJ, Krauss RM, Savage PJ, Smith SC Jr, Spertus JA, Costa F 2005 Diagnosis and management of the metabolic syndrome: an American Heart Association/National Heart, Lung, and Blood Institute Scientific Statement. Circulation 112:2735-2752

3. Alberti KG, Zimmet PZ 1998 Definition, diagnosis and classification of diabetes mellitus and its complications. Part 1: diagnosis and classification of diabetes mellitus provisional report of a WHO consultation. Diabet Med 15:539-553

4. National Cholesterol Education Program (NCEP) Expert Panel on Detection, Evaluation, and Treatment of High Blood Cholesterol in Adults (Adult Treatment Panel III) 2002 Third Report of the National Cholesterol Education Program (NCEP) Expert Panel on Detection, Evaluation, and Treatment of High Blood Cholesterol in Adults (Adult Treatment Panel III) final report. Circulation 106:3143-3421

5. Kahn R, Buse J, Ferrannini E, Stern M 2005 The metabolic syndrome: time for a critical appraisal: joint statement from the American Diabetes Association and the European Association for the Study of Diabetes. Diabetes Care 28:2289-2304

6. Kiess W, Galler A, Reich A, Müller G, Kapellen T, Deutscher J, Raile K, Kratzsch J 2001 Clinical aspects of obesity in childhood and adolescence. Obes Rev 2:29-36

7. Berenson GS 2005 Obesity - a critical issue in preventive cardiology: the Bogalusa Heart Study. Prev Cardiol 8:234-241

8. Kiess W, Gausche R, Keller A, Burmeister J, Willgerodt H, Keller E 2001 Computer-guided, population-based screening system for growth disorders (CrescNet) and on-line generation of normative data for growth and development. Horm Res 56:59-66

9. Keller E, Gausche R, Meigen C, Keller A, Burmeister J, Kiess W 2002 Auxological computer based network for early detection of disorders of growth and weight attainment. J Pediatr Endocrinol Metab 15:149-156

10. Sinha R, Fisch G, Teague B, Tamborlane WV, Banyas B, Allen K, Savoye M, Rieger V, Taksali S, Barbetta G, Sherwin RS, Caprio S 2002 Prevalence of impaired glucose tolerance among children and adolescents with marked obesity. N Engl J Med 346:802-810
11. Reinehr T, Wabitsch M, Andler W, Beyer P, Böttner A, Chen-Stute A, Fromme C, Hampel O, Keller KM, Kilian U, Kolbe H, Lob-Corzilius T, Marg W, Mayer H, Mohnike K, Oepen J, Povel C, Richter B, Riedinger N, Schauerte G, Schmahlfeldt G, Siegfried W, Smuda P, Stachow R, Egmond-Frohlich A, Weiten J, Wiegand S, Witte S, Zindel V, Holl RW 2004 Medical care of obese children and adolescents. APV: a standardised multicentre documentation derived to study initial presentation and cardiovascular risk factors in patients transferred to specialised treatment institutions. Eur J Pediatr 163:308-312

12. Wiegand S, Maikowski U, Blankenstein O, Biebermann H, Tarnow P, Grüters A 2004 Type 2 diabetes and impaired glucose tolerance in European children and adolescents with obesity - a problem that is no longer restricted to minority groups. Eur J Endocrinol 151:199-206

13. Reich A, Müller G, Gelbrich G, Deutscher K, Godicke R, Kiess W 2003 Obesity and blood pressure-results from the examination of 2365 schoolchildren in Germany. Int J Obes Relat Metab Disord 27:1459-1464

14. Reinehr T, Andler W, Denzer C, Siegried W, Mayer H, Wabitsch M 2005 Cardiovascular risk factors in overweight German children and adolescents: relation to gender, age and degree of overweight. Nutr Metab Cardiovasc Dis 15:181-187

15. Weiss R, Dziura J, Burgert TS, Tamborlane WV, Taksali SE, Yeckel CW, Allen K, Lopes M, Savoye M, Morrison J, Sherwin RS, Caprio S 2004 Obesity and the metabolic syndrome in children and adolescents. N Engl J Med 350:2362-2374

16. de Ferranti SD, Gauvreau K, Ludwig DS, Newburger JW, Rifai N 2006 Inflammation and changes in metabolic syndrome abnormalities in US adolescents: findings from the 1988-1994 and 1999-2000 National Health and Nutrition Examination Surveys. Clin Chem 52:1325-1330

17. Lambert M, Paradis G, O'Loughlin J, Delvin EE, Hanley JA, Levy E 2004 Insulin resistance syndrome in a representative sample of children and adolescents from Quebec, Canada. Int J Obes Relat Metab Disord 28:833-841

18. de Ferranti SD, Gauvreau K, Ludwig DS, Neufeld EJ, Newburger JW, Rifai N 2004 Prevalence of the metabolic syndrome in American adolescents: findings from the Third National Health and Nutrition Examination Survey. Circulation 19:2494-2497

19. Zou CC, Liang L, Hong F, Fu JF, Zhao ZY 2005 Serum adiponectin, resistin levels and non-alcoholic fatty liver disease in obese children. Endocr J 52:519-524

20. Chan DF, Li AM, Chu WC, Chan MH, Wong EM, Liu EK, Chan IH, Yin J, Lam CW, Fok TF, Nelson EA 2004 Hepatic steatosis in obese Chinese children. Int J Obes Relat Metab Disord 28:1257-1263

21. Lavine JE, Schwimmer JB 2004 Nonalcoholic fatty liver disease in the pediatric population. Clin Liver Dis 8:549-5ix

22. McCullough AJ 2006 Pathophysiology of nonalcoholic steatohepatitis. J Clin Gastroenterol 40:S17-S29

23. Siebler J, Galle PR 2006 Treatment of nonalcoholic fatty liver disease. World J Gastroenterol 12:2161-2167

24. Hauner H 2005 Secretory factors from human adipose tissue and their functional role. Proc Nutr Soc 64:163-169

25. Kershaw EE, Flier JS 2004 Adipose tissue as an endocrine organ. J Clin Endocrinol Metab 89:2548-2556

26. Zhang Y, Proenca R, Maffei M, Barone M, Leopold L, Friedman JM 1994 Positional cloning of the mouse obese gene and its human homologue. Nature 372:425-432

27. Halaas JL, Gajiwala KS, Maffei M, Cohen SL, Chait BT, Rabinowitz D, Lallone RL, Burley SK, Friedman JM 1995 Weight-reducing effects of the plasma protein encoded by the obese gene. Science 269:543-546

28. Gura T 1999 Obesity research. Leptin not impressive in clinical trial. Science 286:881-882

29. Koerner A, Kratzsch J, Kiess W 2005 Adipocytokines: leptin-the classical, resistin - the controversial, adiponectin-the promising, and more to come. Best Pract Res Clin Endocrinol Metab 19:525-546

30. Lammert A, Kiess W, Böttner A, Glasow A, Kratzsch J 2001 Soluble leptin receptor represents the main leptin binding activity in human blood. Biochem Biophys Res Commun 283:982-988

31. Zastrow O, Seidel B, Kiess W, Thiery J, Keller E, Böttner A, Kratzsch J 2003 The soluble leptin receptor is crucial for leptin action: evidence from clinical and experimental data. Int J Obes Relat Metab Disord 27:1472-1478

32. Kratzsch J, Lammert A, Böttner A, Seidel B, Müller G, Thiery J, Hebebrand J, Kiess W 2002 Circulating soluble leptin receptor and free leptin index during childhood, puberty, and adolescence. J Clin Endocrinol Metab 87:4587-4594

33. Reinehr T, Kratzsch J, Kiess W, Andler W 2005 Circulating soluble leptin receptor, leptin, and insulin resistance before and after weight loss in obese children. Int J Obes (Lond) 29:1230-1235

34. Kratzsch J, Schubring C, Stitzel B, Böttner A, Berthold A, Thiery J, Kiess W 2005 Inverse changes in the serum levels of the soluble leptin receptor and leptin in neonates: relations to anthropometric data. J Clin Endocrinol Metab 90:2212-2217

35. Kratzsch J, Knerr I, Galler A, Kapellen T, Raile K, Korner A, Thiery J, Dotsch J, Kiess W 2006 Metabolic decompensation in children with type 1 diabetes mellitus associated with increased serum levels of the soluble leptin receptor. Eur J Endocrinol 155:609-614

36. Stein K, Vasquez-Garibay E, Kratzsch J, Romero-Velarde E, Jahreis G 2006 Influence of nutritional recovery on the leptin axis in severely malnourished children. J Clin Endocrinol Metab 91:1021-1026

37. Flier JS 1998 Whats in a name? In search of leptins physiological role. J Clin Endocrinol Metab 83:1407-1413

38. Hara K, Yamauchi T, Kadowaki T 2005 Adiponectin: an adipokine linking adipocytes and type 2 diabetes in humans. Curr Diab Rep 5:136-140

39. Kadowaki T, Yamauchi T 2005 Adiponectin and adiponectin receptors. Endocr Rev 26:439-451

40. Böttner A, Kratzsch J, Müller G, Kapellen TM, Blüher S, Keller E, Blüher M, Kiess W 2004 Gender differences of adiponectin levels develop during the progression of 
puberty and are related to serum androgen levels. J Clin Endocrinol Metab 89:40534061

41. Reinehr T, Roth C, Menke T, Andler W 2004 Adiponectin before and after weight loss in obese children. J Clin Endocrinol Metab 89:3790-3794

42. Chu NF, Shen MH, Wu DM, Lai CJ 2005 Relationship between plasma adiponectin levels and metabolic risk profiles in Taiwanese children. Obes Res 13:2014-2020

43. Araki S, Dobashi K, Kubo K, Asayama K, Shirahata A 2006 High molecular weight, rather than total, adiponectin levels better reflect metabolic abnormalities associated with childhood obesity. J Clin Endocrinol Metab 91:5113-5116

44. Pilz S, Horejsi R, Moller R, Almer G, Scharnagl H, Stojakovic T, Dimitrova R, Weihrauch G, Borkenstein M, Maerz W, Schauenstein K, Mangge H 2005 Early atherosclerosis in obese juveniles is associated with low serum levels of adiponectin. J Clin Endocrinol Metab 90:4792-4796

45. Gilardini L, McTernan PG, Girola A, da Silva NF, Alberti L, Kumar S, Invitti C 2006 Adiponectin is a candidate marker of metabolic syndrome in obese children and adolescents. Atherosclerosis 189:401-407

46. Ogawa Y, Kikuchi T, Nagasaki K, Hiura M, Tanaka Y, Uchiyama M 2005 Usefulness of serum adiponectin level as a diagnostic marker of metabolic syndrome in obese Japanese children. Hypertens Res 28:51-57

47. Gregoire FM 2001 Adipocyte differentiation: from fibroblast to endocrine cell. Exp Biol Med (Maywood) 226:997-1002

48. Körner A, Wabitsch M, Seidel B, Fischer-Posovszky P, Berthold A, Stumvoll M, Blüher M, Kratzsch J, Kiess W 2005 Adiponectin expression in humans is dependent on differentiation of adipocytes and down-regulated by humoral serum components of high molecular weight. Biochem Biophys Res Commun 337:540-550

49. Soares AF, Guichardant M, Cozzone D, Bernoud-Hubac N, Bouzaidi-Tiali N, Lagarde M, Geloen A 2005 Effects of oxidative stress on adiponectin secretion and lactate production in 3T3-L1 adipocytes. Free Radic Biol Med 38:882-889

50. Fasshauer M, Paschke R 2003 Regulation of adipocytokines and insulin resistance. Diabetologia 46:1594-1603

51. Iwaki M, Matsuda M, Maeda N, Funahashi T, Matsuzawa Y, Makishima M, Shimomura I 2003 Induction of adiponectin, a fat-derived antidiabetic and antiatherogenic factor, by nuclear receptors. Diabetes 52:1655-1663

52. Lihn AS, Pedersen SB, Richelsen B 2005 Adiponectin: action, regulation and association to insulin sensitivity. Obes Rev 6:13-21

53. Degawa-Yamauchi M, Moss KA, Bovenkerk JE, Shankar SS, Morrison CL, Lelliott CJ, Vidal-Puig A, Jones R, Considine RV 2005 Regulation of adiponectin expression in human adipocytes: effects of adiposity, glucocorticoids, and tumor necrosis factor $\{$ alpha $\}$. Obes Res 13:662-669

54. Nilsson L, Binart N, Bohlooly Y, Bramnert M, Egecioglu E, Kindblom J, Kelly PA, Kopchick JJ, Ormandy CJ, Ling C, Billig H 2005 Prolactin and growth hormone regulate adiponectin secretion and receptor expression in adipose tissue. Biochem Biophys Res Commun 331:1120-1126

55. Xu A, Chan KW, Hoo RL, Wang Y, Tan KC, Zhang J, Chen B, Lam MC, Tse C, Cooper GJ, Lam KS 2005 Testosterone selectively reduces the high molecular weight form of adiponectin by inhibiting its secretion from adipocytes. J Biol Chem 280:18073-18080

56. Berg AH, Scherer PE 2005 Adipose tissue, inflammation, and cardiovascular disease. Circ Res 96:939-949

57. Sjoholm A, Nystrom T 2005 Endothelial inflammation in insulin resistance. Lancet 365:610-612

58. Homma Y 2004 Predictors of atherosclerosis. J Atheroscler Thromb 11:265-270

59. Ford ES, Galuska DA, Gillespie C, Will JC, Giles WH, Dietz WH 2001 C-reactive protein and body mass index in children: findings from the Third National Health and Nutrition Examination Survey, 1988-1994. J Pediatr 138:486-492
60. Moran A, Steffen LM, Jacobs DR Jr., Steinberger J, Pankow JS, Hong CP, Tracy RP, Sinaiko AR 2005 Relation of C-reactive protein to insulin resistance and cardiovascular risk factors in youth. Diabetes Care 28:1763-1768

61. Lambert M, Delvin EE, Paradis G, O'Loughlin J, Hanley JA, Levy E 2004 C-reactive protein and features of the metabolic syndrome in a population-based sample of children and adolescents. Clin Chem 50:1762-1768

62. Hiura M, Kikuchi T, Nagasaki K, Uchiyama M 2003 Elevation of serum C-reactive protein levels is associated with obesity in boys. Hypertens Res 26:541-546

63. Bastard JP, Jardel C, Bruckert E, Blondy P, Capeau J, Laville M, Vidal H, Hainque B 2000 Elevated levels of interleukin 6 are reduced in serum and subcutaneous adipose tissue of obese women after weight loss. J Clin Endocrinol Metab 85:33383342

64. Nemet D, Wang P, Funahashi T, Matsuzawa Y, Tanaka S, Engelman L, Cooper DM 2003 Adipocytokines, body composition, and fitness in children. Pediatr Res 53:148-152

65. Dixon D, Goldberg R, Schneiderman N, Delamater A 2004 Gender differences in TNF-alpha levels among obese vs nonobese Latino children. Eur J Clin Nutr 58:696-699

66. Zinman B, Hanley AJ, Harris SB, Kwan J, Fantus IG 1999 Circulating tumor necrosis factor-alpha concentrations in a native Canadian population with high rates of type 2 diabetes mellitus. J Clin Endocrinol Metab 84:272-278

67. Gerber M, Böttner A, Seidel B, Lammert A, Bär J, Schuster E, Thiery J, Kiess W, Kratzsch J 2005 Serum resistin levels of obese and lean children and adolescents: biochemical analysis and clinical relevance. J Clin Endocrinol Metab 90:4503-4509

68. Levy-Marchal C, Jaquet D 2004 Long-term metabolic consequences of being born small for gestational age. Pediatr Diabetes 5:147-153

69. Jaquet D, Deghmoun S, Chevenne D, Collin D, Czernichow P, Levy-Marchal C 2005 Dynamic change in adiposity from fetal to postnatal life is involved in the metabolic syndrome associated with reduced fetal growth. Diabetologia 48:849855

70. Corbetta S, Bulfamante G, Cortelazzi D, Barresi V, Cetin I, Mantovani G, Bondioni S, Beck-Peccoz P, Spada A 2005 Adiponectin expression in human fetal tissues during mid- and late gestation. J Clin Endocrinol Metab 90:2397-2402

71. Kotani Y, Yokota I, Kitamura S, Matsuda J, Naito E, Kuroda Y 2004 Plasma adiponectin levels in newborns are higher than those in adults and positively correlated with birth weight. Clin Endocrinol (Oxf) 61:418-423

72. Tsai PJ, Yu CH, Hsu SP, Lee YH, Chiou CH, Hsu YW, Ho SC, Chu CH 2004 Cord plasma concentrations of adiponectin and leptin in healthy term neonates: positive correlation with birthweight and neonatal adiposity. Clin Endocrinol (Oxf) 61:88-93

73. Iniguez G, Soto N, Avila A, Salazar T, Ong K, Dunger D, Mericq V 2004 Adiponectin levels in the first two years of life in a prospective cohort: relations with weight gain, leptin levels and insulin sensitivity. J Clin Endocrinol Metab 89:55005503

74. Petridou E, Mantzoros CS, Belechri M, Skalkidou A, Dessypris N, Papathoma E, Salvanos H, Lee JH, Kedikoglou S, Chrousos G, Trichopoulos D 2005 Neonatal leptin levels are strongly associated with female gender, birth length, IGF-I levels and formula feeding. Clin Endocrinol (Oxf) 62:366-371

75. Dunger D, Ong K 2004 Abundance of adiponectin in the newborn. Clin Endocrinol (Oxf) 61:416-417

76. Kamoda T, Saitoh H, Saito M, Sugiura M, Matsui A 2004 Serum adiponectin concentrations in newborn infants in early postnatal life. Pediatr Res 56:690-693

77. Butte NF, Comuzzie AG, Cole SA, Mehta NR, Cai G, Tejero M, Bastarrachea R, Smith EO 2005 Quantitative genetic analysis of the metabolic syndrome in Hispanic children. Pediatr Res 58:1243-1248 